Комп'ютерним $3 D$ моделюванням досліджений процес динамічного балансування кульовими автобалансирами крильчатки осъового вентилятора. Досліджено режими розгону, крейсерсъкого руху і вибігу вентилятора. Оцінена точність балансування на ділянці крейсерсъкого руху. Досліджено вплив сил тяжіння, в'язкого опору руху куль на точність балансування. Оцінений вплив ексиентриситетів бігових доріжок автобалансирів на точність балансування

Ключові слова: освовий вентилятор, кульовий автобалансир, точність балансування, динамічне балансування, автобаланування, перехідний процес

Компьютерным $3 D$ моделированием исследован процесс динамической балансировки двумя шаровыми автобалансирами крыльчатки осевого вентилятора. Исследованы режимы разгона, крейсерского движения и выбега вентилятора. Оценена точность балансировки на уиастке крейсерского движения. Исследовано влияние сил тяжести, вязкого сопротивления движению царов на точность балансировки крыльчатки. Оценено влияние әксцентриситетов беговых дорожек автобалансиров на точность балансировки

Ключевье слова: осевой вентилятор, шаровой автобалансир, точность балансировки, динамическая балансировка, автобалансировка, переходной процесс

口-

\section{ON THE LIMITED ACCURACY OF BALANCING THE AXIAL FAN IMPELLER BY AUTOMATIC BALL BALANCERS}

\author{
L. Olijnichenko \\ Engineer \\ Department of Materials Science and Foundry* \\ E-mail: loga_lubov@ukr.net \\ $\overline{\mathbf{V}}$. H ru ba n \\ PhD, Assistant \\ Department of tractors and agricultural machinery, \\ operating and maintenance \\ Mykolayiv National Agrarian University \\ Georgiya Gongadze str., 9, Mykolayiv, Ukraine, 54020 \\ E-mail: vasilgruban@ukr.net \\ M. L y c h u k \\ $\mathrm{PhD}$, Associate Professor \\ Department of Mathematics and Physics* \\ E-mail:sfg_ı@i.ua \\ V. P i r o g o v \\ $\mathrm{PhD}$, Senior Lecturer \\ Department of Machine Parts and Applied Mechanics* \\ E-mail: pirogovvv@ukr.net \\ *Central Ukrainian National Technical University \\ Universytetskyi ave., 8, Kropivnitskiy, Ukraine, 25006
}

2. Literature review and problem statement

It is shown in [2] that vibrations of axial fans are caused by the usual (static and dynamic) imbalance of the rotating parts of the fan and technological imbalance. Moreover, technological imbalance can be caused by aerodynamic forces arising from the asymmetry of the impellers. It is specified in [3] that the greatest contribution to the vibration of the considered fans is made by usual and aerodynamic imbalances.

The accuracy of statistical balancing of the impeller with an automatic balancer located in the fairing is studied experimentally in [4] with 3D modelling in [5]. The parameters of the axial fan and two automatic balancers dynamically balancing the impeller are optimized in [6]. 3D modelling has been used in the computer-aided design (CAD) and computer-aided engineering (CAE) program SolidWorks. In [7], the process of static and dynamic balancing of the impeller of an axial fan by automatic ball balancers is experimentally

through 3D modelling [13]. 
studied along with the influence of the automatic balancers on the dynamics of the fan in the sections of its acceleration and rundown.

The accuracy of the impeller balancing by the automatic balancers in the cruising range has been estimated. It has been determined that the presence of automatic balancers does not worsen the vibrational state of the fan in the acceleration section and improves it in the sections of cruising and rundown. It has been established that two automatic balances provide the best accuracy of balancing in the cruising range. In this case, the accuracy of balancing is limited by class G 6.3 of the international standard ISO 21940-11:2016 (Mechanical vibration - Rotor balancing - Part 11: Procedures and tolerances for rotors with rigid behaviour).

The tests carried out in [6,7] do not determine to what limiting values it is actually possible to reduce the vibrations of the fan.

Residual vibrations are facilitated by insufficient or excessive balancing capacity of automatic balancers [8], gravity [9], standstill of the balls due to dry friction [10], eccentricity of the raceway [11], external disturbing forces of various nature [12], etc.

In the rotor with an inclined axis of rotation, the action of gravity is unavoidable. The influence of other factors can be minimized at the stages of manufacturing and installing automatic balancers in the fan.

To establish the limiting values to which it is actually possible to reduce the vibrations of the fan it is necessary to carry out the experiments described in [7] under «ideal» conditions. Such conditions are provided by using 3D CAD modelling in SolidWorks with the Cosmos Motion module [13].

\section{The aim and objectives of the study}

The aim of the work is to carry out a computer study of the process of dynamic balancing of the impellers of axial fans of the series VO 06-300 (Ukraine) with automatic ball balancers. This will allow evaluating the influence of gravity and other factors on the accuracy of balancing the rotor.

To achieve this aim, it is necessary to solve such problems:

- to analyse the effect of automatic balancers on the vibrational state of the axial fan by $3 \mathrm{D}$ modelling and to compare the simulation results with the results of the field experiment;

- to evaluate the influence of gravity forces and viscous drag forces on the motion of the balls on the accuracy of balancing the rotor;

- to assess the influence of the eccentricity of the automatic balancer raceway on the accuracy of balancing the rotor.

\section{Methods of studying the process of dynamic balancing of the impeller of an axial fan with automatic ball balancers}

\subsection{Description of the 3D model of the axial fan and} the automatic ball balancers

For the experiments, a 3D model of the fan is used (Fig. 1), as described in [6].

The model consists of a frame (Fig. 1, $a$ ), a protective casing with the motor housing (Fig. 1, b); an impeller, a rotor, and automatic balancer housings in an assembly (a composite rotor, Fig. 1,c).

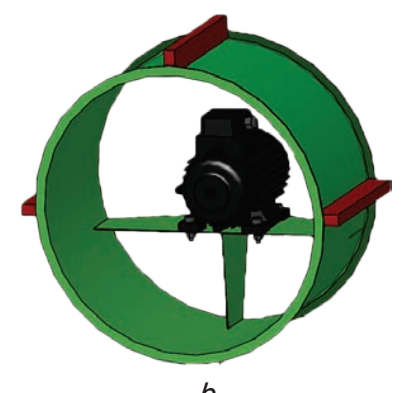

$b$

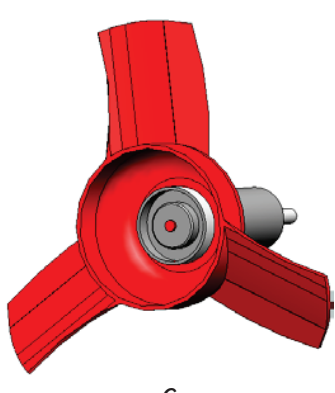

$c$
Fig. 1. The 3D model of the axial fan [6]:

$a$ - the frame; $b$ - the protective casing with the motor housing; $c$ - the rotor, the impeller and the cases of the automatic balancers in an assembly (a composite rotor)

Parts of the 3D model: the protective casing with the motor housing $-12.2 \mathrm{~kg}$; the composite rotor $-2.0 \mathrm{~kg}$. The mass values correspond to the test bench [7].

The value of the cruising speed of the impeller is indicated in specific experiments.

By default, this speed is $25 \mathrm{r} / \mathrm{s}$.

The protective casing is maintained by isotropic elastic viscous bearings. The total stiffness and viscosity coefficients of the bearings are chosen under the condition that the resonance speeds of the impeller rotation on the test bench and in the 3D model are the same. These speeds [7] are $n_{1}=8.4 \mathrm{~Hz}$ and $n_{2}=12.7 \mathrm{~Hz}$. The selected coefficients are the following: the rigidity forces of the supports $-29 \mathrm{~N} / \mathrm{mm}$; the forces of viscous resistance of the supports $-0.06 \mathrm{~N} \cdot \mathrm{s} / \mathrm{mm}$; the moment of rigidity of the supports $-11,500 \mathrm{~N} \cdot \mathrm{mm} / \mathrm{deg}$; the moment of forces of viscous resistance of the supports $1 \mathrm{~N} \cdot \mathrm{s} \cdot \mathrm{mm} / \mathrm{deg}$.

One automatic balancer is installed in the fairing of the impeller, and the second is mounted on the rotor shank. Each automatic balancer consists of a body (Fig. 2, a), a cover (Fig. 2, b) and six identical balls (Fig. 2,c).
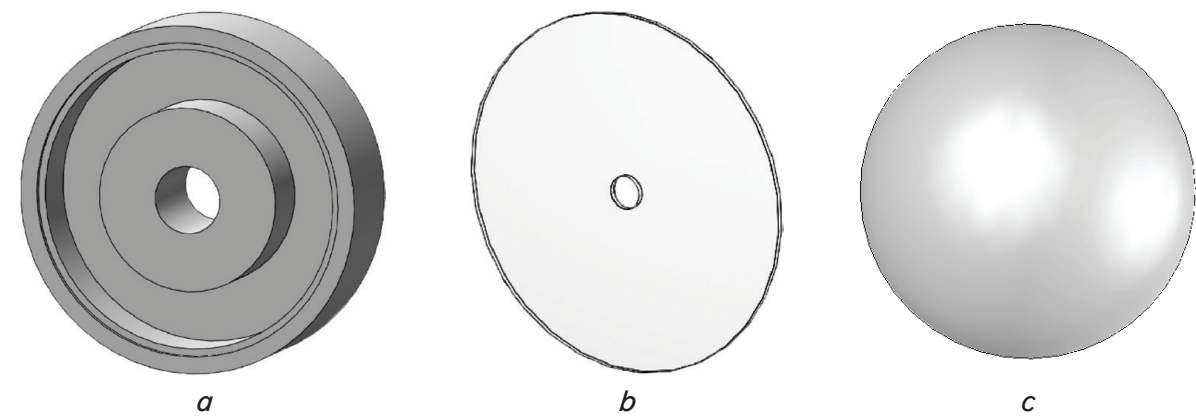

C

Fig. 2. Parts of the 3D model of automatic balancers: $a$ - the AB body; $b$ - the cover; $c$ - a ball 
The parameters of the automatic balancers corresponding to the test bench [7] are the following:

$$
n=6, m=6.93 \mathrm{~g}, d=11.9 \mathrm{~mm}, D_{i m}=68 \mathrm{~mm}, D_{s h}=64 \mathrm{~mm} \text {, }
$$

where $n$ is the number of the balls; $m(\mathrm{~g})$ is the mass, $d(\mathrm{~mm})$ is the diameter of the ball; $D_{i m}$ and $D_{s h}(\mathrm{~mm})$ are the diameters of the raceways of the automatic balancers.

Herewith, the balancing capacities of the automatic balancers on the side of the impeller and the shank are, respectively, $S_{\max i m}=878.6 \mathrm{~g} \cdot \mathrm{mm}$ and $S_{\max s h}=776.4 \mathrm{~g} \cdot \mathrm{mm}$.

The value of the coefficient of the viscous drag force for the motion of the ball is indicated in specific experiments. By default, this factor is $0.0001 \mathrm{~N} \cdot \mathrm{s} / \mathrm{mm}$.

The method for evaluating the vibrational state of the fan.

The vibrational state is estimated from the vibration velocities measured in 3 control points (Fig. 3):

1 - on the axis of the rotor rotation in the correction plane of the automatic balancer located on the impeller side;

2 - on the axis of the rotor rotation in the correction plane of the automatic balancer located on the shank side;

3 - on the fan protective casing

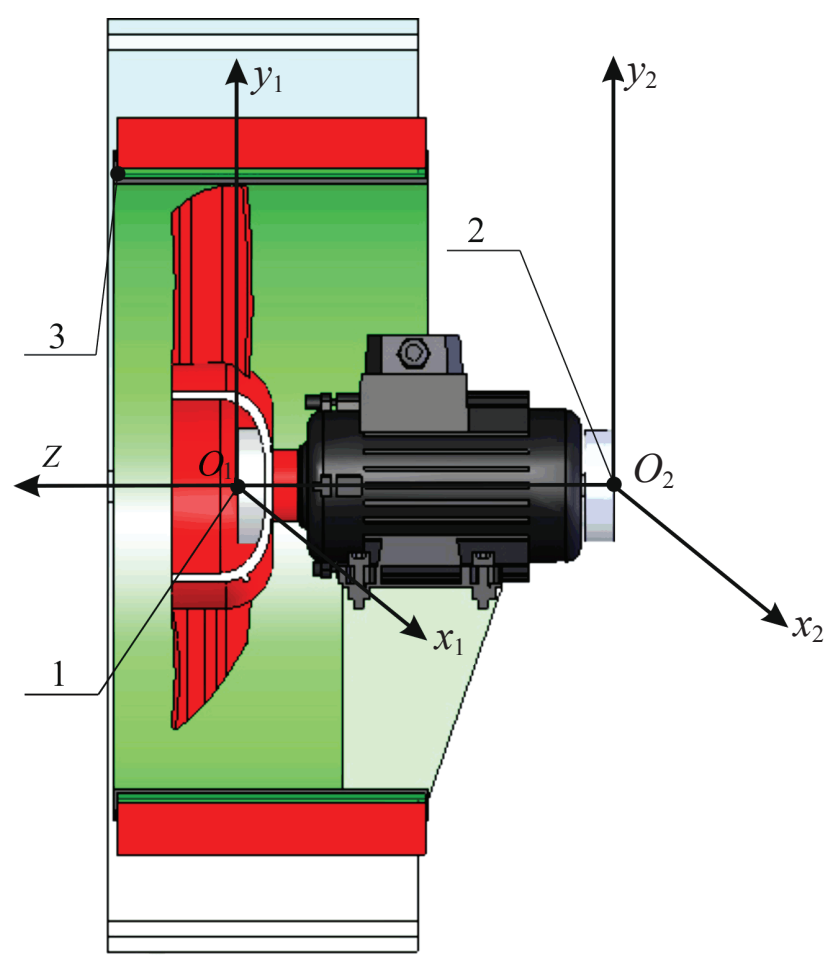

Fig. 3. Location of the control points for measuring vibration velocities: 1 - on the impeller side; 2 - on the shank side; 3 - on the protective casing

The control points on the longitudinal axis of the rotor move mainly in planes perpendicular to the longitudinal axis (in the correction planes).

At point 1, the quality of balancing the composite rotor is evaluated by the first automatic balancer; at point 2 , it is estimated by the second one. At point 3 , the quality of the dynamic balancing of the composite rotor is evaluated by two automatic balancers. At this point, oscillations create imbalances both from the impeller side and from the shank side. The vibration values are estimated in accordance with the recommendations of the international standard ISO 21940-11:2016.
The vibration at the reference point is assessed as to

- the vibration velocity (the value of the vibration velocity module at time $t) ; V_{j}(t), / j=1,2,3 /$;

- the mean square value of the vibration velocity for the time interval $T$ :

$$
\bar{V}_{j}=\sqrt{\frac{1}{T} \int_{0}^{T} V_{j}^{2}(t) \mathrm{d} t}, \quad / j=1,2,3 / ;
$$

- the peak value of the vibration velocity in the time interval $\left[t_{1}, t_{2}\right], t_{2}>t_{1}$ :

$$
V_{\max j}=\max _{t \in\left[t_{1}, t_{2}\right]} V_{j}(t), \quad / j=1,2,3 / .
$$

The vibration velocity at the control point, with an equal time step, is calculated by the internal means of the COSMOS Motion module. The data are exported to an Excel spreadsheet. The averaged and peak values are calculated in MS Excel.

The modelling of dynamic imbalance.

In the experiments, by default, dynamic imbalance is created in each correction plane by two masses $-m_{s t}=17.4 \mathrm{~g}$ and $m_{d}=8 \mathrm{~g}$. The masses are located in these planes as shown in Fig. 4.

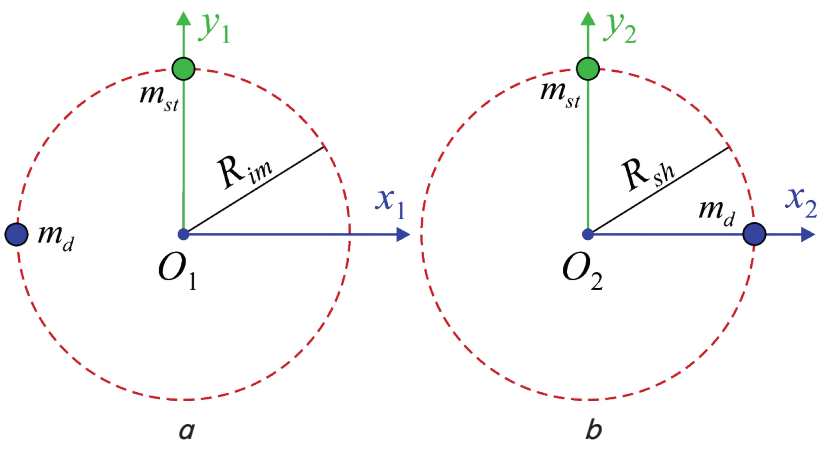

Fig. 4. Simulation of imbalances in the correction planes: $a$ - the impeller; $b$ - the shank

The distances from the masses to the longitudinal axis of the fan are equal to $R_{i m}=43.0 \mathrm{~mm}$ and $R_{s h}=38.5 \mathrm{~mm}$. The masses are selected so that in the absence of automatic balancers the vibration velocity at the control points on the steady-state motion exceeds the maximum permissible value $(6.3 \mathrm{~mm} / \mathrm{s})$ at least 2.5 times. This corresponds to an increase in the maximum permissible imbalance of the impeller by at least one class of balancing accuracy (ISO 21940-11:2016).

The values of the imbalances in the correction planes are equal to [7]:

$S_{i m}=823.5 \mathrm{~g} \mathrm{~mm}$ and $S_{s h}=737.3 \mathrm{~g} \mathrm{~mm}$.

Herewith,

$$
\begin{aligned}
& \frac{S_{\text {im }}}{S_{\max i m}} \cdot 100 \%=\frac{823.5}{878.6} \cdot 100 \%=94 \%, \\
& \frac{S_{s h}}{S_{\max s h}} \cdot 100 \%=\frac{737.3}{776.4} \cdot 100 \%=95 \%
\end{aligned}
$$

- the balancing tanks can hold at least $5 \%$ and not more than $10 \%$ of the maximum possible imbalances in their correction 
planes. A small stock of balancing capacity minimizes the residual imbalance caused by substandard performance of the automatic balancers [8].

The test bench configurations are the following: 1 - without automatic balancers; 2 - with automatic balancers. The absence of automatic balancers is ensured by the absence of balls in them.

\section{2. Description of the experiments}

Each experiment lasts 38 seconds. During the experiment, the impeller does the following: accelerates for $1 \mathrm{~s}$; rotates at cruising speed for $12 \mathrm{~s}$; stops at $25 \mathrm{~s}$.

Based on the results of each experiment for control points 1,2 , and 3 , the corresponding vibration velocity diagrams are constructed.

To assess the vibrational state of the fan, the following sections are identified in the vibration velocity diagram (Fig. 5):

I - from the start of the rotor to the onset of automatic balancing $t \in[0,3)$;

II - from the moment of the onset of automatic balancing before the start of the deceleration of the rotor $t \in[3,13)$;

III - from the beginning of the deceleration of the rotor to the complete stopping $t \in[13,38]$.

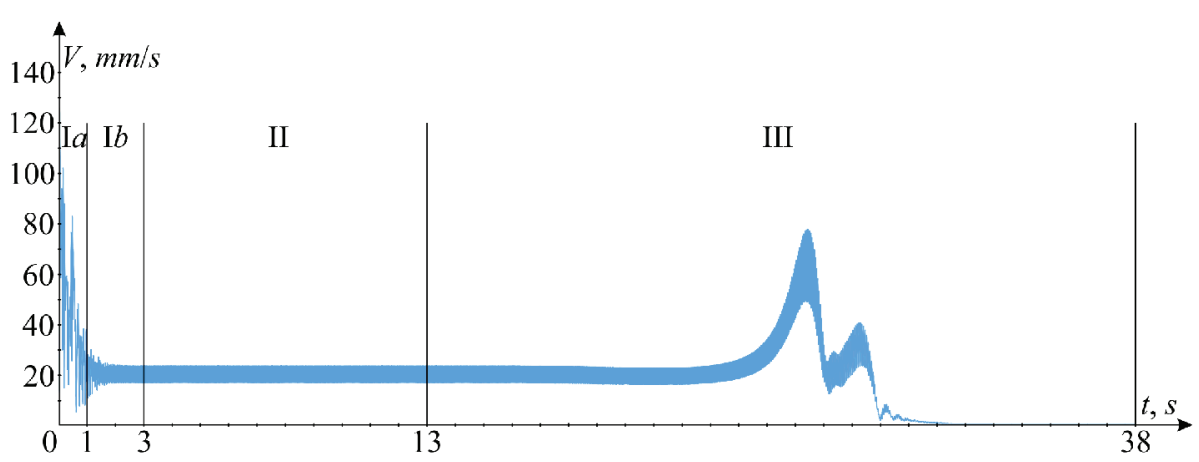

Fig. 5. Division of the vibration velocity diagram into sections (readings taken at benchmark point 3 of the test bench without automatic balancers) the accuracy of balancing.

racteristics obtained for the 2nd configuration of the bench are compared with the characteristics obtained for the 1st configuration adopted for the base configuration. The results obtained are compared with the results of the corresponding full-scale experiments obtained in [7].

Experiment 1. Evaluation of the effect of automatic balancers on the modes of acceleration and deceleration of the rotor. The influence of automatic balancers is estimated from the vibration characteristics of sections Ia, Ib, I, and III.

Experiment 2. Evaluation of the accuracy of balancing. The accuracy of the balancing is assessed in section II (from the moment of the onset of automatic balancing before the start of the deceleration of the rotor).

Experiments 3. Evaluation of the influence of gravity on

The influence of gravity on the accuracy of balancing the rotor is estimated for the 2nd configuration of the test bench (for balancing the composite rotor with two automatic balancers). The vibrational characteristics of the fan in section II (on which the automatic balancing occurs) are used. Simulation is performed twice - with «switched on» and «off» gravity. Theoretically, with «off» gravity, the two automatic balancers should completely eliminate the vibrations at the control points. Therefore, residual vibrations with «switched off» gravity forces characterize the error of 3D modelling. Residual vibrations with «included» gravity forces characterize the effect of gravity on the accuracy of balancing (accurate to 3D simulation errors).

Experiment 3.1.3D simulation is performed for a fixed imbalance $\left(m_{s t}=17.4 \mathrm{~g}\right.$ and $\left.m_{d}=8 \mathrm{~g}\right)$ for different cruising rotor speeds: $n=15,25,50$ and $100 \mathrm{r} / \mathrm{s}$. The effect of gravity on the accuracy of balancing the rotor at different rotor speeds is estimated.

In turn, section I is divided into:

Ia - the segment of the acceleration of the rotor (from the start of the rotor to the cruising speed) $t \in[0,1)$;

$\mathrm{Ib}$ - the section of unsteady cruising motion (automatic balancing after the acceleration of the rotor) $t \in[0,3)$.

In the presence of automatic balancers, these sections are real, and in the absence of automatic balancers, they are conditional.

The vibrational state of the fan is estimated from the vibration velocity diagram by the following characteristics:

- in sections Ia, Ib, and I - by the mean square value of the vibration velocity;

- in section II - by the peak value of the vibration velocity (the vibration velocity itself is a periodic or constant time function);

- in section III - by the values of the vibration velocity at peaks 1 and 2 .

The first group of experiments repeats the actual experiments carried out in [7] under «ideal» conditions. In these experiments, the cruising speed of the rotor, like on the test bench, is $25 \mathrm{r} / \mathrm{s}$. Gravity is «on». Experiments are carried out for two test bench configurations - in the absence and presence of automatic balancers. The results of $3 \mathrm{D}$ modelling determine the vibration characteristics of the fan. The cha-
Experiment 3.2.3D simulation is performed at rotor speeds of 15,20 and $25 \mathrm{r} / \mathrm{s}$ for different imbalances, making up $0,25,50$ and 75 per cent of the imbalance created by the masses of $m_{s t}=17.4 \mathrm{~g}$ and $m_{d}=8 \mathrm{~g}$. The case $\ll 100 \%$ is covered by experiment 3.1. The influence of gravity on the accuracy of balancing the rotor is estimated at various imbalances and at different rotor speeds.

Experiment 3. 3. 3D simulation is performed at a fixed rotor speed of $n=20 \mathrm{r} / \mathrm{s}$ for various imbalances that make up 0,25 , 50,75 and 100 per cent of the imbalance created by the masses of $m_{s t}=17.4 \mathrm{~g}$ and $m_{d}=8 \mathrm{~g}$. The coefficient of viscous drag force of the ball changes: $0.0005 \mathrm{~N} \cdot \mathrm{s} / \mathrm{mm} ; 0.001 \mathrm{~N} \cdot \mathrm{s} / \mathrm{mm}$. The case $\ll 0.0001 \mathrm{~N} \cdot \mathrm{s} / \mathrm{mm} \gg$ is covered by experiments 3.1 and 3.2 .

The influence of gravity on the accuracy of the balancing of the rotor is evaluated for various imbalances in the rotor and for various viscous drag forces for the motion of the ball.

Additionally, each experiment is described in the presentation of its results.

4. 3. The method for assessing the effect of eccentricity of automatic balancer raceways on the accuracy of balancing the rotor

The effect of the eccentricity of the automatic balancer raceways on the accuracy of the balancing of the composite 
rotor is estimated. The utilized effect is that an automatic balancer set with eccentricity $e_{j}, / j=i m, s k /$ forces the composite rotor to rotate around its centre [11]. This occurs with a sufficient balancing capacity of the automatic balancer. In this case, control points 1 and 2 on the longitudinal axis of the rotor rotate around the corresponding centres of the automatic balancers. The radii of rotation of points 1 and 2, respectively, are equal to $e_{i m}$ and $e_{s k}$. Therefore, the vibration velocity at control points 1 and 2 after the onset of automatic balancing is equal to:

$$
V_{1}=e_{i m} \cdot 2 \pi n, V_{2}=e_{s k} \cdot 2 \pi n \text {. }
$$

From (4), we find the maximum eccentricity of the raceway:

$$
e_{\max }=V_{\max } /(2 \pi n),
$$

where for the accuracy class of the balance $\mathrm{G} \mathrm{N}$, the maximum vibration velocity module is $V_{\max }=N \mathrm{~mm} / \mathrm{s}$.

If the eccentricity of the raceway exceeds the maximum value, the corresponding automatic balancer will create residual vibrations that exceed the permissible ones.

The maximum eccentricity of the raceway is determined at the rotor speeds of $n=15,25,50,75,100 \mathrm{r} / \mathrm{s}$ and the balance accuracy classes G 1, G 2.5, G 6.3, and G 16 .

\section{The results of studying the balancing of the impeller of an axial fan with automatic ball balancers}

5.1. The influence of automatic balancers on the vibrational state of the rotary machine in the sections of acceleration and rundown

Fig. 6 shows the vibration velocity diagram of control point 3 of the test bench with automatic balancers. The diagram for the remaining control points has a similar form. From the form of the diagrams shown in Fig. 5, 6 it follows that in the presence of automatic balancers there are generally lower vibration velocities.

Since the simultaneous operation of two automatic balancers is studied, then readings are taken only at control point 3 .

Fig. 7 shows diagrams of the vibration velocities of point 3 in the section from the start of the rotor to the onset of automatic balancing.

The vibration velocities (Table 1 ) are evaluated separately in each section of $\mathrm{Ia}, \mathrm{Ib}$ and, in general, in segment $\mathrm{I}$. Table 1 shows by how much (in \%) the mean square value of the vibration velocity changes (the velocity of vibration of configuration 2 is compared to 1 ).

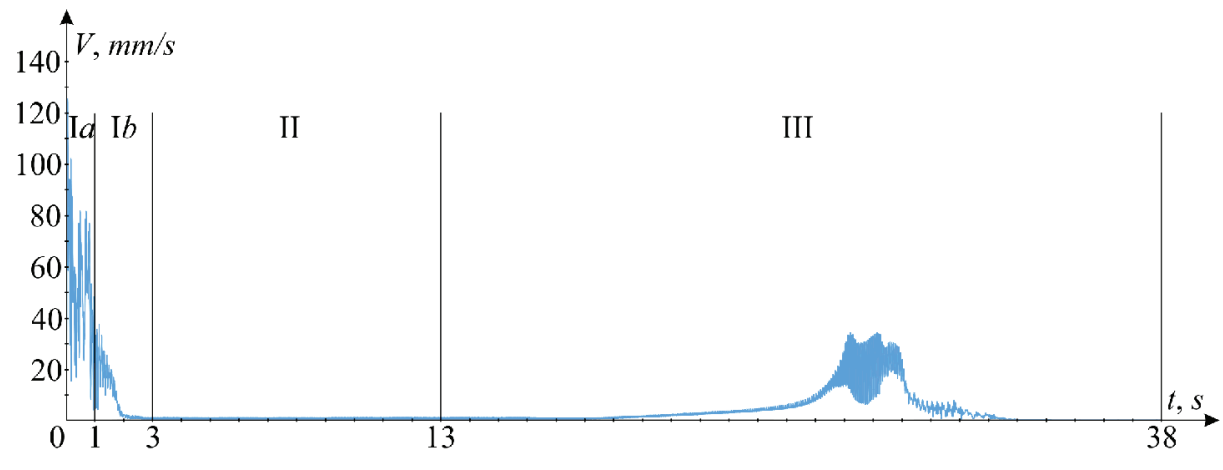

Fig. 6. A diagram of the vibration velocity of control point 3 of the tests bench with two automatic balancers

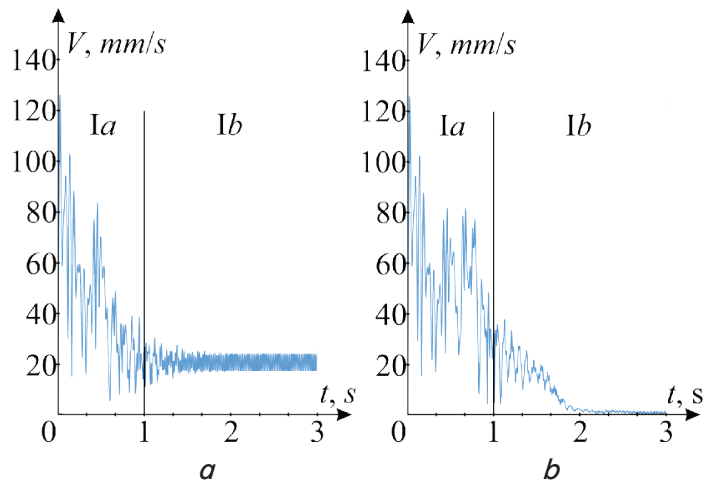

Fig. 7. Diagrams of the vibration velocities of point 3 in section I: $a-$ without automatic balancers; $b$ - with two automatic balancers

Table 1

Vibration characteristics of the fan in sections la, lb, and I

\begin{tabular}{|l|c|c|c|c|c|c|}
\hline \multirow{2}{*}{$\begin{array}{c}\text { Test bench con- } \\
\text { figuration }\end{array}$} & \multicolumn{5}{|c|}{ Ia } & \multicolumn{3}{c|}{ Ib } & \multicolumn{2}{c|}{ I (Ia+Ib) } \\
\cline { 2 - 7 } & $\begin{array}{c}\bar{V}_{3}, \\
\mathrm{~mm} / \mathrm{s}\end{array}$ & $\begin{array}{c}\Delta \bar{V}_{3}, \\
\%\end{array}$ & $\begin{array}{c}\bar{V}_{3}, \\
\mathrm{~mm} / \mathrm{s}\end{array}$ & $\begin{array}{c}\Delta \bar{V}_{3}, \\
\%\end{array}$ & $\begin{array}{c}\bar{V}_{3}, \\
\mathrm{~mm} / \mathrm{s}\end{array}$ & $\begin{array}{c}\Delta \bar{V}_{3}, \\
\%\end{array}$ \\
\hline 1 - without ABs & 44.0 & 0 & 20.18 & 0 & 28.1 & 0 \\
\hline $\begin{array}{l}2-\text { with ABs - } \\
\text { the 3D model }\end{array}$ & 52.85 & 20 & 7.68 & -62 & 22.72 & -19 \\
\hline $\begin{array}{l}3-\text { with ABs - } \\
\text { the test bench [7] }\end{array}$ & - & - & - & - & - & -7 \\
\hline
\end{tabular}

Table 1 shows that automatic balancers affect the vibrational state of the fan in the following ways:

- worsen it in section Ia (acceleration);

- improve it in section Ib;

- improve it in the entire section I.

At the same time, in «ideal» conditions, automatic balancers improve the vibrational state of the fan in section I 2.7 times better than under the conditions of the full-scale experiment.

Below are fragments of the vibration velocity diagrams in the rundown section:

- the vicinity of peak 1 (Fig. 8);

- the vicinity of peak 2 (Fig. 9).

The values of the vibration velocities at resonant peaks 1 and 2 are listed in Table 2 . Therein, the values of the vibration velocities at peaks 1 and 2 are decreased by the percentage of automatic balancers. 


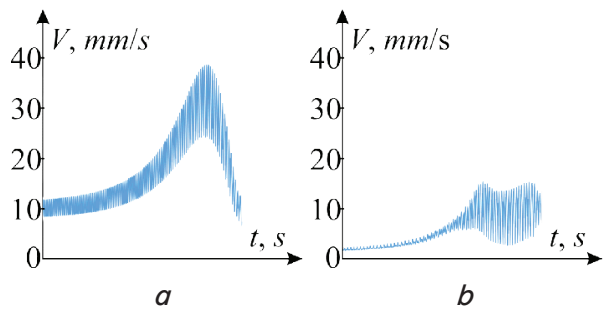

Fig. 8. Fragments of the vibration velocity diagrams in the rundown section in the vicinity of peak 1 for the test bench: $a$ - without automatic balancers; $b$ - with two automatic balancers

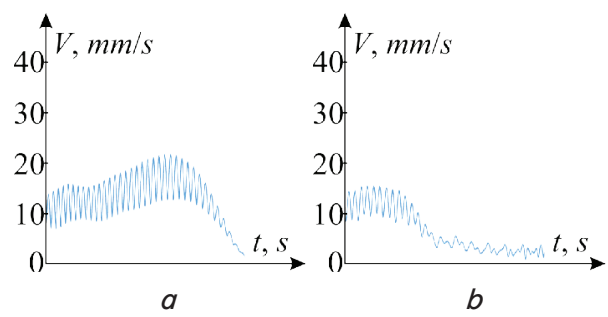

Fig. 9. Fragments of the vibration velocity diagrams in the rundown section in the vicinity of peak 2 for the test bench: $a$ - without automatic balancers; $b$ - with two automatic balancers

Table 2

The values of the vibration velocities at resonance peaks 1 and 2 in the rundown section

\begin{tabular}{|l|c|c|c|c|}
\hline \multirow{2}{*}{$\begin{array}{c}\text { Test bench con- } \\
\text { figuration }\end{array}$} & \multicolumn{4}{|c|}{ The rundown section } \\
\cline { 2 - 5 } & $\begin{array}{c}V_{\max 3}, \\
\mathrm{~mm} / \mathrm{s}\end{array}$ & $\begin{array}{c}\Delta V_{\max 3}, \\
\%\end{array}$ & $\begin{array}{c}V_{\max 3}, \\
\mathrm{~mm} / \mathrm{s}\end{array}$ & $\begin{array}{c}\Delta V_{\max 3} \\
\%\end{array}$ \\
\hline 1 - without ABs & 34.89 & 0 & 23.69 & 0 \\
\hline $\begin{array}{l}2-\text { with ABs - } \\
\text { the 3D model }\end{array}$ & 13.51 & -61 & 12.87 & -46 \\
\hline $\begin{array}{l}3-\text { with ABs - } \\
\text { the test bench [7] }\end{array}$ & - & -39 & - & -30 \\
\hline
\end{tabular}

Table 2 shows that automatic balancers improve the rundown mode at both peak 1 and peak 2 . At the same time, in «ideal» conditions, the improvement is 1.5 times better than under the conditions of the full-scale experiment.

5. 2. Evaluation of the accuracy of dynamic balancing of the rotor by automatic balancers in the cruising range

The results of experiment 2 are listed in Table 3.

Table 3

Results of experiment 2

\begin{tabular}{|l|c|c|c|}
\hline \multirow{2}{*}{$\begin{array}{c}\text { Test bench config- } \\
\text { uration }\end{array}$} & \multicolumn{3}{|c|}{$\begin{array}{c}\text { Peak values of vibration velocities } \\
\text { at the control points, } V_{\max }, \mathrm{mm} / \mathrm{s}\end{array}$} \\
\cline { 2 - 4 } & 1 & 2 & 3 \\
\hline 1 - without ABs & 16.05 & 16.56 & 17.07 \\
\hline 2 - with ABs & 0.14 & 0.22 & 0.23 \\
\hline
\end{tabular}

The vibration velocities (Table 4) are assessed in accordance with the recommendations of ISO 21940-11:2016.
Table 4

Evaluation of accuracy of automatic balancing

\begin{tabular}{|c|c|c|c|c|c|c|}
\hline \multirow{2}{*}{$\begin{array}{c}\text { Test bench } \\
\text { configuration }\end{array}$} & \multicolumn{6}{|c|}{$\begin{array}{c}\text { Decrease of vibration velocities at the control } \\
\text { points, times }\end{array}$} \\
\cline { 2 - 7 } & \multicolumn{3}{|c|}{ Test bench [7] } & \multicolumn{4}{|c|}{3 D model } \\
\cline { 2 - 8 } & 1 & 2 & 3 & 1 & 2 & 3 \\
\hline 2 - with ABs & 5.4 & 5.5 & 5.7 & 114 & 75 & 74 \\
\hline
\end{tabular}

Table 3 (checkpoint 3 ) shows that

- in the absence of automatic balancers, the vibration velocity exceeds the maximum permissible values of $6.3 \mathrm{~mm} / \mathrm{s}$ (ISO 21940-11:2016) 2.7 times;

- in the presence of automatic balancers, the vibration velocity is reduced at least 74 times in relation to the absence of automatic balancers and 27 times with respect to the maximum permissible values.

With 3D modelling, the accuracy of balancing the rotor is 16 times higher than on the test bench.

5. 3. Evaluation of the influence of gravity on the accuracy of balancing the rotor

The results of experiment 3.1 are shown in Table 5 .

Table 5

Results of experiment 3.1 for $m_{s t}=17.4 \mathrm{~g}$ and $m_{d}=8 \mathrm{~g}$

\begin{tabular}{|c|c|c|c|c|c|c|}
\hline \multirow{2}{*}{$\begin{array}{c}\text { Rotational } \\
\text { speed of the } \\
\text { impeller, r/s }\end{array}$} & \multicolumn{5}{|c|}{ Vibration velocities in the control } \\
\cline { 2 - 7 } & 1 & 2 & 3 & 1 & 2 & 3 \\
\cline { 2 - 7 } & with gravity $\mathrm{mm} / \mathrm{s}$ \\
\hline 15 & 0.36 & 0.52 & 0.65 & 0.01 & 0.01 & 0.01 \\
\hline 20 & 0.23 & 0.29 & 0.47 & 0.01 & 0.01 & 0.02 \\
\hline 25 & 0.14 & 0.22 & 0.23 & 0.02 & 0.02 & 0.03 \\
\hline 50 & 0.09 & 0.13 & 0.14 & 0.04 & 0.03 & 0.05 \\
\hline 100 & 0.06 & 0.07 & 0.08 & 0.04 & 0.04 & 0.05 \\
\hline
\end{tabular}

The residual vibration velocities, detected in the absence of gravity, allow estimating the accuracy of 3D modelling. The vibration velocities are calculated with an error of $0.01 \div 0.05 \mathrm{~mm} / \mathrm{s}$. With an increase in the cruising speed of the rotor rotation, the error in the calculations increases somewhat.

Table 5 shows that in the range of the rotor speeds of $15 \div 100 \mathrm{r} / \mathrm{s}$ :

- gravity strongly worsens the accuracy of balancing the rotor at the lowest speeds of rotation;

- with increasing the rotor speed, the effect of gravity on the accuracy of balancing quickly decreases;

- at the lowest rotational speeds of the rotor, the forces of gravity limit the accuracy of balancing by class $\mathrm{G} 1$.

The results of experiment 3.2 are given in Table 6 .

From Table 6 (and Table 5 at $\omega=20 \mathrm{r} / \mathrm{s}$ ), it can be seen that the gravity most worsens the accuracy of balancing the rotor in the absence or with small imbalance of the rotor. When the rotor rotates in the speed range of $15 \div 25 \mathrm{r} / \mathrm{s}$, the gravity of the rotor is limited by class G 1 . 
Results of experiment 3.2

\begin{tabular}{|c|c|c|c|c|c|c|c|}
\hline \multirow{2}{*}{ Masses of imbalances } & \multicolumn{5}{|c|}{ Rotor speed, $\mathrm{r} / \mathrm{s}$} \\
\hline $\mathrm{g}$ & & 15 & 20 & 25 & 15 & 20 & 25 \\
\cline { 3 - 8 } & & \multicolumn{6}{|c|}{$\begin{array}{c}\text { The highest instantaneous value } \\
\text { of the vibration velocity module } \\
\text { at control point 3, mm/s }\end{array}$} \\
\hline \multirow{2}{*}{$m_{s t}=13.05 \mathrm{~g}, m_{d}=6 \mathrm{~g}$} & 75 & 0.32 & 0.22 & 0.11 & 0.02 & 0.04 & 0.05 \\
\hline$m_{s t}=8.7 \mathrm{~g}, m_{d}=4 \mathrm{~g}$ & 50 & 0.37 & 0.30 & 0.26 & 0.02 & 0.04 & 0.05 \\
\hline$m_{s t}=4.35 \mathrm{~g}, m_{d}=2 \mathrm{~g}$ & 25 & 0.68 & 0.55 & 0.47 & 0.02 & 0.04 & 0.05 \\
\hline$m_{s t}=0 \mathrm{~g}, m_{d}=0 \mathrm{~g}$ & 0 & 0.64 & 0.58 & 0.45 & 0.02 & 0.04 & 0.05 \\
\hline
\end{tabular}

The results of experiment 3.3 are given in Table 7 .

Table 7

Results of experiment 3. 3

\begin{tabular}{|c|c|c|c|c|c|}
\hline \multirow{2}{*}{ Masses of imbalances } & \multicolumn{4}{|c|}{$\begin{array}{c}\text { Coefficients of force of viscous resis- } \\
\text { tance, N.s/mm }\end{array}$} \\
\hline $\mathrm{g}$ & & 0.0005 & 0.0010 & 0.0005 & 0.0010 \\
\cline { 3 - 6 } & & \multicolumn{3}{|c|}{$\begin{array}{c}\text { The highest instantaneous value } \\
\text { of the vibration velocity module } \\
\text { at control point 3, mm/s }\end{array}$} \\
\hline$m_{s t}=17.4 \mathrm{~g}, m_{d}=8 \mathrm{~g}$ & 100 & 0.73 & 0.92 & 0.04 & 0.05 \\
\hline$m_{s t}=13.05 \mathrm{~g}, m_{d}=6 \mathrm{~g}$ & 75 & 0.28 & 0.47 & 0.04 & 0.05 \\
\hline$m_{s t}=8.7 \mathrm{~g}, m_{d}=4 \mathrm{~g}$ & 50 & 0.60 & 0.89 & 0.04 & 0.05 \\
\hline$m_{s t}=4.35 \mathrm{~g}, m_{d}=2 \mathrm{~g}$ & 25 & 1.17 & 1.72 & 0.04 & 0.05 \\
\hline$m_{s t}=0 \mathrm{~g}, m_{d}=0 \mathrm{~g}$ & 0 & 0.58 & 0.61 & 0.04 & 0.05 \\
\hline
\end{tabular}

Table 7 shows that the gravity forces most worsen the accuracy of balancing the rotor in the case of imbalance, which is $25 \%$ of the balancing capacity of the automatic balancers. Increasing the viscous resistance to ball motion worsens the accuracy of balancing. When the rotor rotates at a speed of $20 \mathrm{r} / \mathrm{s}$, the gravity of the rotor is limited by accuracy class G 2.5 (residual vibrations lie in the range of $1.0 \div 2.5 \mathrm{~mm} / \mathrm{s}$ ). Obviously, the deterioration in the accuracy of balancing is associated with the standstill of the balls. With large viscous drag forces, the balls slowly drift to the automatic balancing position.

\subsection{The effect of the eccentricity of the automatic} balancer raceway on the accuracy of balancing

By formula 5, we have found the maximum eccentricity values of the raceway. The results of the calculations are listed in Table 8 .

Table 8 shows that fast-rotating rotors need automatic balancers to be installed more accurately.

\begin{tabular}{|c|c|c|c|c|}
\hline \multirow{2}{*}{$\begin{array}{c}\text { Rotational speed } \\
\text { of the impeller, r/s }\end{array}$} & \multicolumn{4}{|c|}{$e_{\max }, \mathrm{mm}$} \\
\cline { 2 - 5 } & $\mathrm{G} 1$ & $\mathrm{G} 2.5$ & $\mathrm{G} 6.3$ & $\mathrm{G} 16$ \\
\hline 15 & 0.0106 & 0.027 & 0.067 & 0.170 \\
\hline 20 & 0.008 & 0.020 & 0.05 & 0.127 \\
\hline 25 & 0.0064 & 0.016 & 0.04 & 0.102 \\
\hline 50 & 0.0032 & 0.008 & 0.02 & 0.051 \\
\hline 75 & 0.0021 & 0.005 & 0.013 & 0.034 \\
\hline 100 & 0.0016 & 0.004 & 0.01 & 0.025 \\
\hline
\end{tabular}

It is recommended that the eccentricities of the tracks should be less than 2.5 times the magnitude given in Table 8 . In this case, the residual vibrations of control points 1 and 2 that are caused only by the eccentricities of the raceways will lie within the range of a higher class of balancing accuracy.

For example, for accuracy class $\mathrm{G} 6,3$, the residual vibrations (only from the eccentricities of the raceways) will lie in the range of $1 \div 2.5 \mathrm{~mm} / \mathrm{s}$.

\section{Discussion of the results of the process of balancing a rotor with the horizontal axis of rotation by automatic ball balancers}

An effective method for studying the vibrational state of the fan with automatic balancers is $3 \mathrm{D}$ computer simulation of the dynamics.

The analysis of the vibrational state of the fan in section I, from the start of the rotor to the onset of automatic balancing, has shown that

a) in the acceleration section (section Ia, $0-1 \mathrm{~s}$ ), the automatic balancers increase the mean square vibration velocity by $20 \%$;

b) in the part of the cruising non-stationary motion (section $\mathrm{Ib}, 1-3 \mathrm{~s})$, the automatic balances reduce the mean square vibration velocity by $62 \%$;

c) in the whole section I, the automatic balancers reduce the vibration velocity by $19 \%$.

Under «ideal» conditions, automatic balancers can improve the vibrational state of the fan in section I 2.7 times better than in the conditions of the full-scale experiment.

The analysis of the vibrational state of the fan during the rundown has shown that the automatic balancers reduce the vibration velocity of the two peaks of the vibration velocity diagram by $61 \%$ and $46 \%$, respectively. The latter is explained by the fact that during the rundown there is a standstill of the balls and the balls remain in the balancing positions almost to the stop of the rotor.

Under «ideal» conditions, automatic balancers improve the rundown mode 1.5 times better than in the full-scale experiment conditions.

In this part, the $3 \mathrm{D}$ computer simulation confirms the results of the full-scale experiment described in [7]. 
With 3D modelling (in «ideal» conditions), the rotor's balancing accuracy is 16 times higher than on the field test bench.

The effect of gravity on the accuracy of balancing the rotor quickly decreases with increasing the cruising speed of the impeller. The gravity forces most of all worsen the accuracy of the rotor balancing in the absence or low inertia of the rotor. When the rotor rotates in a speed range of $15 \div 25 \mathrm{r} / \mathrm{s}$, the gravity forces limit the accuracy of the rotor balancing by accuracy class $\mathrm{G} 1$ (residual vibrations lie in the range of $0.4 \div 1.0 \mathrm{~mm} / \mathrm{s}$ ).

With increasing forces of viscous resistance to the motion of the balls, the effect of gravity on the accuracy of the rotor balancing increases. When the rotor rotates at a speed of $20 \mathrm{r} / \mathrm{s}$, the gravity limits the accuracy of the rotor balancing by accuracy class G 2.5 (residual vibrations lie in the range of $1.0 \div 2.5 \mathrm{~mm} / \mathrm{s}$ ). The deterioration of the balancing accuracy is due to the slowing of the reaction of the balls to the disequilibrium. At high forces of viscous resistance, the balls slowly drift to the automatic balancing position.

The residual vibration velocities caused by gravity only decrease with increasing the speed of the rotor rotation (with any forces of viscous resistance to the motion of the balls).

On fast-rotating rotors, it is necessary to install automatic balancers more accurately. Residual vibration velocities that are caused only by eccentricities of the raceways increase directly in proportion to the rotor speed.

The residual vibration of a fan balanced by two automatic balancers, as in [7], is mainly caused not by gravity. The probable causes of residual vibrations [8-12] are the following: inaccuracy in the production of automatic balancers; inaccuracy of installing the automatic balances on the rotor; standstill of the balls on the raceway, etc. Vibrations that are caused by these factors can be minimized at the stage of manufacturing and assembling the fan and the automatic balancers.

The obtained results can be applied to improve the vibration characteristics of fans of the series VO 06-300 (Ukraine) during the manufacturing stage and to enhance the accuracy of balancing the fan with automatic ball balancers.

The main limitation of the research is the possibility of using the obtained results only for a certain series of fans. However, it is offset by the fact that this series has a wide range of sizes and the results obtained can be applied to any of them. In the future, it is planned to develop a mathematical model for this type of rotary machine with two ABs and conduct a computational experiment.

\section{Conclusion}

The research has been carried out for an axial fan of the series VO 06-300 (Ukraine) with the nominal speed of the impeller rotation of $25 \mathrm{r} / \mathrm{s}$.

1. The computer simulation of the fan dynamics in the absence and presence of automatic balancers has confirmed the qualitative results of a previous full-scale experiment. Thus, the presence of automatic balancers reduces the following:

- the average quadratic value of the vibration velocity in the section from the start of the rotor to the onset of automatic balancing (19\% for the 3D modelling; $7 \%$ for the field experiment);

- the vibration velocity values at two peaks when the rotor is running down (by $61 \%$ and $46 \%$ for the 3D modelling; by $39 \%$ and $30 \%$ for the field experiment);

- the peaks of the vibration velocities in the section of the start of automatic balancing (74 times in the 3D modelling; 5.4 times in the field experiment).

2. The computer simulation of the dynamics of the axial fan with the «on» and «off» gravity forces has allowed determining the following:

- the effect of gravity on the accuracy of balancing the impeller decreases rapidly with increasing the cruising speed of the impeller;

- when increasing the forces of viscous resistance to the motion of the balls, the effect of gravity on the accuracy of the rotor balancing increases;

- at low speeds of rotation ( $15 \mathrm{r} / \mathrm{s})$, the impeller can be balanced not better than by accuracy class G 2.5, but at the rated speed of $25 \mathrm{r} / \mathrm{s}$, it is balanced according to accuracy class G 1 .

The residual vibration velocities that are caused only by gravity decrease with increasing the rotor speed.

3. The residual vibration velocities that are caused only by the eccentricities of the raceways increase directly proportionally to the rotor speed. Therefore, fast-turning rotors need a more precise installation of automatic balancers. It is recommended to reduce the eccentricity of the raceway of the automatic balancer at least 2.5 times in relation to the maximum permissible value. Residual vibration velocities in the automatic balancing mode (up to $3 \mathrm{~mm} / \mathrm{s}$ ) on the test fan are mostly caused by gravity. The probable causes of residual vibration velocities are eccentricities of the raceways of the automatic balancers, standstill of the balls (lack of reaction to small unbalances), etc. Therefore, residual vibration velocities can be reduced at the stages of manufacturing and installing automatic balancers into a fan.

1. Polyakov V., Skvortsov L. Pumps and Fans. Moscow: Stroyizdat, 1990. 336 p.

2. Ziborov K., Vanga G., Marenko V. Imbalance As A Major Factor Influencing The Work Rotors Mine Main Fan // Modern engineering. Science and education. 2013. Issue 3. P. 734-740. URL: http://mmese-2017.spbstu.ru/mese/2013/734_740.pdf

3. Korneev N., Polyakova E. Aerodynamic disbalance of the turbocompressor as the reason of lowering of power indexes of internal combustion engines // Machine Builder. 2014. Issue 1. P. 51-57.

4. Yatsun V., Filimonikhin G. Experimental study of the efficiency of equilibration of impellers of axial fans by passive auto-balancers // Konstruyuvannya, vyrobnytstvo ta eksplyatatsiya silskohospodarskykh mashyn. 2008. Issue 38. P. 100-105.

5. Filimonikhin G., Yatsun V. Chyslove modeliuvannia protsesu zrivnovazhennia kulovymy avtobalansyramy krylchatky osovoho ventyliatora [Numerical modeling of the balancing process by ball-type auto-balancers of an axial fan impeller] // Naukovyi visnyk natsionalnoho hirnychoho universytetu. 2008. Issue 10. P. 72-77. 
6. Olijnichenko L., Filimonikhin G. Optimization of parameters of autobalancers for dynamic balancing of impeller of axial fans by 3D modeling // Eastern-European Journal of Enterprise Technologies. 2014. Vol. 6, Issue 7 (72). P. 12-17. doi: 10.15587/ 1729-4061.2014.30498

7. Experimental study of the process of the static and dynamic balancing of the axial fan impeller by ball auto-balancers / Olijnichenko L., Goncharov V., Sidei V., Horpynchenko O. // Eastern-European Journal of Enterprise Technologies. 2017. Vol. 2, Issue 1 (86). P. 42-50. doi: 10.15587/1729-4061.2017.96374

8. An increase of the balancing capacity of ball or roller-type auto-balancers with reduction of time of achieving auto-balancing / Goncharov V., Filimonikhin G., Nevdakha A., Pirogov V. // Eastern-European Journal of Enterprise Technologies. 2017. Vol. 1, Issue 7 (85). P. 15-24. doi: 10.15587/1729-4061.2017.92834

9. Chung J. Effect of gravity and angular velocity on an automatic ball balancer // Proceedings of the Institution of Mechanical Engineers, Part C: Journal of Mechanical Engineering Science. 2005. Vol. 219, Issue 1. P. 43-51. doi: 10.1243/095440605x8333

10. Chan T. C., Sung C. K., Chao P. C. P. Friction effect on ball positioning of an automatic balancer in optical disk drives // Microsystem Technologies. 2012. Vol. 18, Issue 9-10. P. 1343-1351. doi: 10.1007/s00542-012-1540-y

11. Bykov V. G., Kovachev A. S. Dynamics of a rotor with an eccentric ball auto-balancing device // Vestnik St. Petersburg University: Mathematics. 2014. Vol. 47, Issue 4. P. 173-180. doi: 10.3103/s1063454114040037

12. Influence of external excitations on ball positioning of an automatic balancer / Sung C. K., Chan T. C., Chao C. P., Lu C. H. // Mechanism and Machine Theory. 2013. Vol. 69. P. 115-126. doi: 10.1016/j.mechmachtheory.2013.05.009

13. Chang K.-H. Motion Simulation and Mechanism Design with COSMOSMotion 2007. Norman, Oklahoma, Paperback: Schroff Development Corporation, 2008. 142 p. 